\title{
Body Image in Eating Disorders: The Influence of Exposure to Virtual-Reality Environments
}

\author{
José Gutiérrez-Maldonado, Ph.D., Marta Ferrer-García, \\ Alejandra Caqueo-Urízar, Ph.D., ${ }^{2}$ and Elena Moreno ${ }^{3}$
}

\begin{abstract}
The aim of this article was to study the effect of virtual-reality exposure to situations that are emotionally significant for patients with eating disorders (ED) on the stability of body-image distortion and body-image dissatisfaction. A total of $85 \mathrm{ED}$ patients and 108 non-ED students were randomly exposed to four experimental virtual environments: a kitchen with low-calorie food, a kitchen with high-calorie food, a restaurant with lowcalorie food, and a restaurant with high-calorie food. In the interval between the presentation of each situation, body-image distortion and body-image dissatisfaction were assessed. Several $2 \times 2 \times 2$ repeated measures analyses of variance (high-calorie vs. low-calorie food $\times$ presence vs. absence of people $\times$ ED group vs. control group) showed that ED participants had significantly higher levels of body-image distortion and body dissatisfaction after eating high-calorie food than after eating low-calorie food, while control participants reported a similar body image in all situations. The results suggest that body-image distortion and body-image dissatisfaction show both trait and state features. On the one hand, ED patients show a general predisposition to overestimate their body size and to feel more dissatisfied with their body image than controls. On the other hand, these body-image disturbances fluctuate when participants are exposed to virtual situations that are emotionally relevant for them.
\end{abstract}

\section{Introduction}

B ODY-IMAGE DISTURBANCES HAVE BEEN frequently and strongly associated with the development and maintenance of eating disorders (ED). ${ }^{1,2} \mathrm{Hilde} \mathrm{Bruch}^{3}$ was the first to note that the dysfunctional experience of body image was a central aspect in anorexia nervosa. Some years later, Rosen ${ }^{4 p 190}$ stated that "body image disturbance is essentially what distinguishes them [ED] from other psychological conditions that occasionally involve eating abnormalities and weight loss". Body-image disturbances are now regarded as a key element in $\mathrm{ED}^{5-7}$ and are part of the criteria for diagnosing both anorexia and bulimia. ${ }^{8}$ Body size overestimation and body dissatisfaction are risk factors for both ED development ${ }^{9,10}$ and relapse. ${ }^{11-15}$ Furthermore, research has demonstrated their implications for prognosis, ${ }^{16}$ indicating that a persistent dysfunctional body image after treatment is a longterm factor in negative outcomes.

Given the importance of body-image disturbances in the onset and maintenance of eating disorders, a great deal of research has been carried out into the relationship between the two, although the results have not been consistent or conclusive. $^{11,16-21}$ To explain these inconsistencies, several authors have suggested that body image might be more a state than a trait, ${ }^{20,22-24}$ and may change according to situational or emotional variables, ${ }^{25}$ especially in participants who are concerned about their body shape and/or weight. ${ }^{26}$ In fact, Myers and Biocca ${ }^{27}$ referred to the "elastic body image" nearly 20 years ago, and more recently other authors ${ }^{28-30}$ have stressed that trait and state components coexist in the body-image construct.

Few studies have addressed the instability of body-image disturbance or its sensitivity to situational conditions. In fact, most research has assumed that body-image disturbance is stable; the dominant paradigm has, historically, been the "trait perspective." ${ }^{31,32}$ Nevertheless, several studies have provided evidence of fluctuations in body-image disturbance. Studies have analyzed the influence that eating low- and high-calorie food, ${ }^{12,33-35}$ being exposed to low- and highcalorie food, ${ }^{36-38}$ and being exposed to photographs of low- and high-calorie food ${ }^{39-41}$ exerts on body-image disturbances. As Fett et al. ${ }^{42}$ stress, the literature shows that food

\footnotetext{
${ }^{1}$ Department of Personality, Assessment and Psychological Treatments, University of Barcelona, Barcelona, Spain.

${ }^{2}$ Department of Phylosophy and Psychology, University of Tarapacá, Arica, Chile.

${ }^{3}$ Hospital Clínic de Barcelona, Barcelona, Spain.
} 
intake is an important factor that causes changes in bodyimage dissatisfaction. ${ }^{43-46}$ Exposure to situations that imply the scrutiny of others using guided imagination ${ }^{31}$ and exposure to attractive women ${ }^{47-53}$ have also been studied. Many of these studies suggest that body image, or some of its components, can indeed be understood as a state rather than as a trait. However, not all authors would concur; ${ }^{49,51}$ in fact, comparison of the results is particularly difficult because of the differences in the samples and body-image assessment methods used. Finally, as studies with clinical participants tend to have very small samples, their conclusions should be treated with caution.

In order to explore the notion of body-image disturbances as a state using virtual-reality (VR) technology, we designed a selection of VR environments that simulated everyday situations that are emotionally significant for people with eating disorders. Unlike the conventional methods used in the studies mentioned above (e.g., in-vivo exposure to the situation, exposure to photographs and media images, exposure via guided imagination, and so on), VR not only possesses good ecological validity, as it exposes subjects to interactive threedimensional environments that simulate real situations, but also presents good internal validity, as it allows strict control over the variables. In this way, VR overcomes the main drawback of laboratory studies, that is, their artificiality. The main shortcomings of exposure via guided imagination are the lack of control over what participants are actually thinking about, and the imagination difficulties that participants may experience; the most important disadvantages of in-vivo exposure are the difficulty of controlling the variables and the risk that participants may refuse to face a situation that is unpleasant for them. However, VR must prove its capacity to produce emotional and related behavioral responses in the virtual situation that are similar to those elicited by the real situation before they can be used systematically. ${ }^{54}$ With this aim in mind, we conducted a previous validation of several virtual environments (VE), including the ones used in the present study. This validation aimed to test whether virtual situations were able to elicit differential levels of anxiety and depression in patients with ED and in controls without psychopathology. ${ }^{55}$ Several authors have stressed the close relation between anxiety/depression and $\mathrm{ED},{ }^{56,57}$ and a relationship between the presence of a negative mood and an increase in body-image disturbances has often been found. With regard to this connection, the literature shows that anxiety and depressive states influence body-image disturbances, usually increasing levels of body overestimation and especially body dissatisfaction. ${ }^{58-60}$ What is more, mood changes during the day are closely associated with concurrent body-image disturbances. ${ }^{25-61}$

In this validation of the VR environments, ED patients displayed higher levels of anxiety and depressed mood after eating (in both the high- and low-calorie-food modes) and after visiting the swimming pool than in the neutral room. In contrast, controls only showed a significant increase in anxiety in the swimming pool, probably due to the well-known "normative dissatisfaction" ${ }^{\prime 2}$ that a high percentage of women feel with their bodies. These results show that VEs with emotionally significant contextual cues for people with ED (e.g., high-calorie food, lean people) are able to activate their dysfunctional schemas regarding body image and negative emotions associated with the body, especially depression and anxiety. ${ }^{63,64}$
After confirming the occurrence of emotional reactivity during the visits to the VEs, the main objective of the present study was to test whether VR technology is a suitable vehicle for investigating how the two most commonly studied bodyimage disturbances, that is, perceptual body-image distortion and body-image dissatisfaction, ${ }^{11,65,66}$ change depending on the situation to which participants are exposed, and also to determine whether the responses to situations differ in ED patients and non-ED controls. We specifically wanted to test the impact of: (a) the kind of food (high calorie versus low calorie), and (b) the presence or absence of other people on subjects' body-image disturbances while eating, either alone or with friends, in a VE.

Recent research ${ }^{42,67}$ has shown that in-vivo exposure to food produces emotional responses in ED patients. Our validation study ${ }^{55}$ aimed to add to the research on the influence of exposure to food on emotional responses using VR technology. The results obtained with both in-vivo and VR exposure appears to be similar. Continuing this line of research, the present study extends the analysis of the influence of food exposure to body-image disturbances in ED patients.

Several research groups, such as Riva et al. ${ }^{6-77}$ and Perpiña et al., ${ }^{78-80}$ have already developed VR environments for the treatment of body-image disturbances and for assessing the changes obtained. The results of these research groups corroborate the usefulness of VR technology in this field. Authors such as Murray and Gordon ${ }^{81}$ have compared the influence of immersive versus desktop presentation of VR environments on perceptual awareness of the body, finding significant differences in several body features depending on the mode of presentation, and adding evidence of the usefulness of VR technology in the study of body-image changes. Our main objective was also to investigate body-image changes using VR exposure; however, our research focuses on the study of the stability of body-image disturbances, specifically in ED patients, across virtual situations that are likely to be emotionally significant for them. Although the results obtained may have implications for treatment, our main aims are to increase our knowledge of the functioning of body-image distortion and body-image dissatisfaction in ED, and to highlight the usefulness of VR exposure in the study of body-image flexibility.

Body-image distortion is the inability to perceive body size accurately. It can be understood as the discrepancy between perceived and objective body size. Body dissatisfaction refers to the degree to which somebody likes or dislikes the size and shape of his/her body, and can be understood as the discrepancy between ideal and perceived body image.

\section{Method}

\section{Participants}

Participants were 136 students from the faculty of psychology at the University of Barcelona and 85 patients with eating disorders. All participants were female. The following exclusion criteria were applied to the control group: history of or current eating disorder or similar symptoms (assessed by self-report); risk of suffering from an ED (Eating Attitudes Test-26 > 20); and overweight (body mass index [BMI] $>25$; $\mathrm{WHO}, 1998)$ or underweight (BMI < 18; WHO, 1998). The final control group comprised 108 students. 
Table 1. Mean Age, BMI, And EAT-26 Scores of CONTROls AND THE ED Groups

\begin{tabular}{lllllr}
\hline Group & & Min. & Max. & M & SD \\
\hline Control & Age & 20 & 31 & 22.18 & 2.05 \\
& BMI & 18.03 & 25 & 21.77 & 1.82 \\
& EAT-26 & 0 & 18 & 2.98 & 4.11 \\
& $n=108$ & & & & \\
ED (AN) & Age & 13 & 32 & 19.27 & 5.39 \\
& BMI & 12.76 & 21.83 & 18.22 & 1.75 \\
& EAT-26 & 0 & 68 & 36.24 & 21.57 \\
& $n=49$ & & & & \\
ED (BN) & Age & 15 & 28 & 20.50 & 2.33 \\
& BMI & 18.58 & 31.95 & 23.00 & 3.19 \\
& EAT-26 & 2 & 71 & 23.64 & 22.15 \\
& $n=22$ & & & & \\
ED (EDNOS) & Age & 13 & 21 & 15.93 & 1.97 \\
& BMI & 18.03 & 35.85 & 20.89 & 4.45 \\
& EAT-26 & 9 & 70 & 49.14 & 14.76 \\
& $n=14$ & & & & \\
Total ED & Age & 13 & 32 & 19.04 & 4.82 \\
& BMI & 12.76 & 35.85 & 19.9 & 3.41 \\
& EAT-26 & 0 & 71 & 35.11 & 22.14 \\
& $n=85$ & & & & \\
& $n=8$
\end{tabular}

ED, eating disorders; $\mathrm{AN}$, anorexia nervosa; $\mathrm{BN}$, bulimia nervosa; EDNOS, eating disorder not otherwise specified; BMI, body mass index; EAT-26, Eating Attitudes Test-26.

The clinical group comprised 85 ED patients receiving treatment in different hospitals and private clinics in Barcelona, Spain (Hospital Clinic, Hospital Germans Tries i Pujol, Centre ABB, and Centre Labor). Specifically, the group included 49 women with anorexia nervosa (AN), 22 with bulimia nervosa $(\mathrm{BN})$, and 14 with a non-specified eating disorder (EDNOS). Means for age and BMI are shown in Table 1.

\section{Virtual environments}

We developed a selection of VEs to simulate real-life situations that were emotionally significant for ED patients, in order to produce or enhance body-image distortion and body-image dissatisfaction. As patients with ED are known to show anxiety and body-image concerns during exposure to high-calorie food, as well as in situations in which their body is on display or in which they come into contact with other people, ${ }^{12,82,83}$ we chose these elements as contextual cues. The combination of the variables food (no food, high-calorie food, and low-calorie food) and people (no other people present and other people present) gave rise to the different conditions or VE. ${ }^{84}$

Information about the elements needed to obtain clinically significant VEs was obtained from a survey administered to 68 ED patients from the Hospital Germans Tries i Pujol and the Hospital Clinic of Barcelona. The survey compiled data about distal and proximal cues (the situations, the objects and characters present in a situation, and the thoughts generated by a situation) that produced the most body-image discomfort. Events that most frequently appeared were: showing one's own body to others (frequency $=117$ ); comparing oneself to other girls (frequency $=38$ ); and eating (frequency $=37$ ). More detailed information about the specific situations was also obtained. This survey information was used to improve the original VEs, and more interactivity and dialogs were included.

In the present study, we used five virtual scenarios: four experimental VEs (the low-calorie kitchen, the high-calorie kitchen, the low-calorie restaurant, and the high-calorie restaurant) and a training room (neutral environment where participants are trained to move and interact in the VE). We chose these situations because we specifically wanted to analyze the impact of eating "forbidden" (high-calorie) and "allowed" (low-calorie) food on body-image disturbances and to test whether the presence or absence of other people enhances this potential impact (see Figure 1).

\section{Assessment}

The Eating Attitudes Test-26 ${ }^{85}$ (EAT-26) is the reduced version of the Eating Attitudes Test ${ }^{86}$ (EAT-40). The correlation between EAT-40 and EAT-26 is $0.98 .^{85}$ The main objective of this self-administered questionnaire is to detect ED symptoms in non-clinical samples. The reduced version contains 26 items, and participants can choose between six possible answers that range from "never" to "always." The total test score distinguishes between patients with anorexia and the normal population and between patients with bulimia and the normal population. It is recommended for use as a screening instrument, ${ }^{85,87}$ with a cut-off point of $20 .{ }^{88}$ EAT-26 has a very high internal consistency ${ }^{85}$ (Cronbach's $\alpha=0.90$ ). In this study, the Spanish translation of the reduced version of the EAT was used. ${ }^{89}$ A recent validation of the Spanish version of this instrument was conducted by Jorquera et al. ${ }^{90}$ with a sample of 1,069 women and 1,012 men aged 11 to 19 years. They found high internal consistency for the total sample (Cronbach's $\alpha=0.87$ ) and individually, both for women (Cronbach's $\alpha=0.90$ ) and men (Cronbach $\alpha=0.80$ ).

The Body Image Assessment Software (BIAS) ${ }^{91,92}$ is a computer program developed to assess body-image disturbances. The program displays on the computer screen both side and frontal views of a scaled female human figure, which is proportional to the participant's objective body measures. The image can be adjusted by independently modifying six body parts in the frontal view (head, arms, breasts, waist, hips, and legs) and five body parts in the side view (head, breasts, waist, hips, and legs) by using the keyboard. The program proposes two visual-assessment tasks: the perceived body-size assessment and the ideal body-size assessment. In the first, participants are asked to modify several frontal and side body parts in order to make a human figure as similar as possible to their real body image. In the second task, participants modify frontal and side body parts to make a human figure that represents their ideal body image. The discrepancy between their objective and perceived body size provides information about the level of perceptual distortion, and the discrepancy between their perceived and ideal body size provides information on the level of body-image dissatisfaction. Both scales show high internal consistency ${ }^{92}$ (Cronbach's $\alpha=0.917$ for the body-image distortion scale and 0.943 for the body-dissatisfaction assessment scale).

\section{Procedure}

The control sample was recruited from among psychology students at the University of Barcelona. Participants were volunteers, and were rewarded with extra course credits. The 


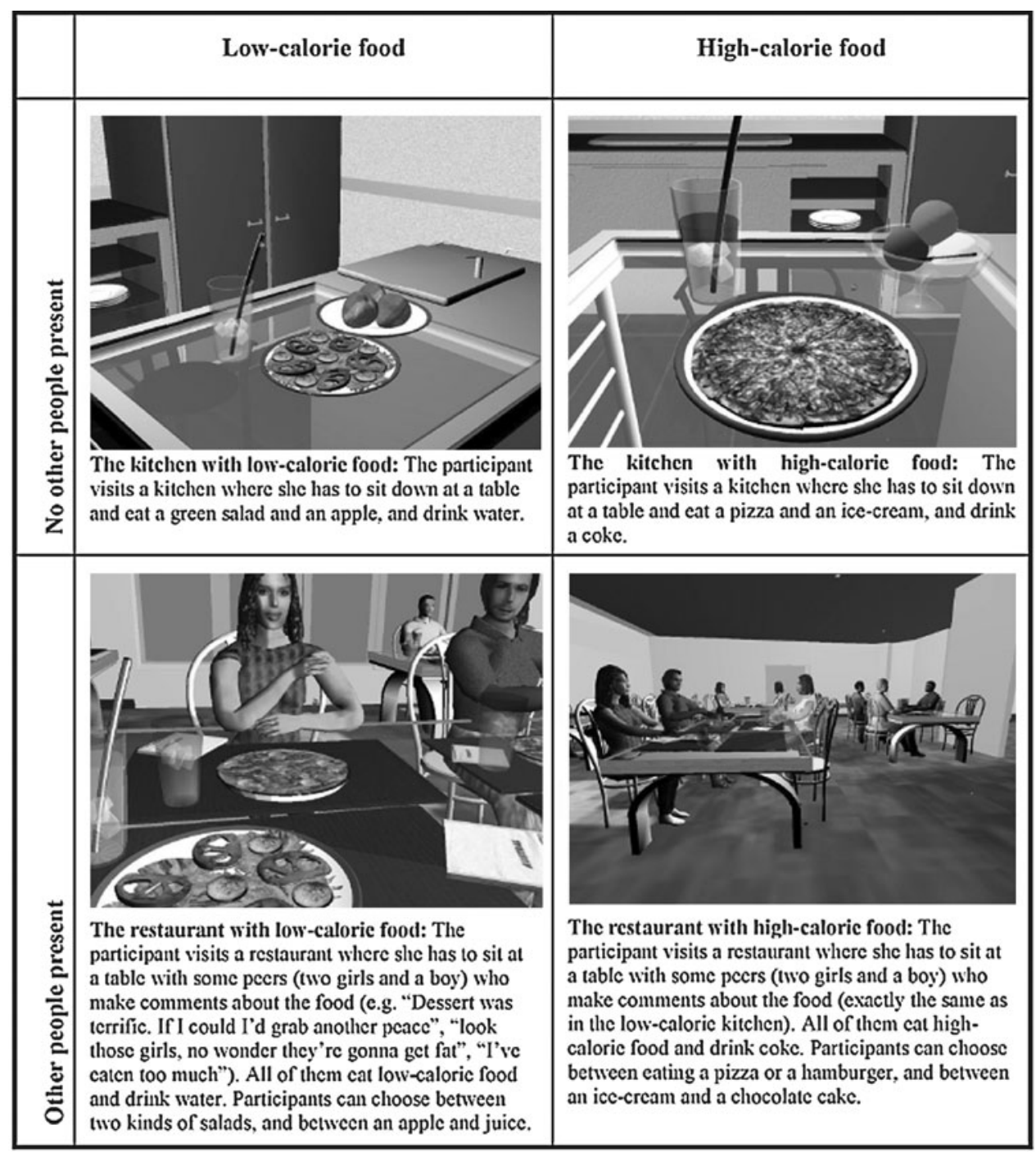

FIG. 1. Pictures of the experimental virtual environments used in the study.

ED sample was recruited from among ED patients being treated at several hospitals and private clinics in Barcelona. All participants signed an informed consent form. When participants were under 18, informed consent was obtained from their parents. Participants were also informed that if at any time they wished to withdraw from the experiment they could do so without any detriment to their treatment in the case of the patients, or to their academic grades in the case of the students.

Tests were administered in two stages. In the first stage, participants were asked to complete a battery of tests including the EAT-26, and were measured and weighed in order to obtain their BMI and the different measures of frontal and side body parts required by the BIAS software. In the second stage, participants were exposed to the VEs. First, they visited the neutral VE, and anxiety (STAI-S), ${ }^{93}$ depression (CDB), ${ }^{94}$ and body-image disturbances (BIAS) were assessed for the first time. The objective of this first administration was to allow participants to familiarize themselves with the VEs and with the measurement instruments used in the study. Exposure and manipulation of one's own body image is in itself a complex and stressful task for ED patients, especially when it occurs immediately after their objective measures have been taken. Increased levels of discomfort were expected at least in the first administration of the BIAS, and so the corresponding results were not taken into account in the subsequent analyses. In the next stage, the four experimental VEs were presented randomly. In the interval between the presentations of each environment, participants filled in the STAI-S, CDB, and BIAS again. After visiting each VE, they were also asked about their thoughts and feelings in the situation. For the purposes of this study, only the EAT-26 and BIAS data were analyzed.

\section{Data analysis}

Several $2 \times 2 \times 2$ repeated measures analyses of variance (ANOVA) were conducted in order to test whether participants' body-image distortion and body-image dissatisfaction changed, depending on the kind of food (low calorie or high calorie), the presence or absence of people in the environment, and the group (ED patients or controls without ED). 
Table 2. Mean Scores for Body-Image Distortion and Body-Image Dissatisfaction of ED Patients and Controls in the Low- and High-Calorie Kitchen, and in the Low- and High-Calorie Restaurant Situations

\begin{tabular}{|c|c|c|c|c|c|c|c|}
\hline & \multirow[b]{2}{*}{ Food } & \multirow[b]{2}{*}{ Situation } & \multirow[b]{2}{*}{ People } & \multicolumn{2}{|c|}{ BI distortion } & \multicolumn{2}{|c|}{ BI dissatisfaction } \\
\hline & & & & M & SD & M & SD \\
\hline \multirow[t]{4}{*}{ ED } & \multirow[t]{2}{*}{ Low calorie } & Kitchen & Without & 13.54 & 0.95 & -16.72 & 1.54 \\
\hline & & Restaurant & With & 14.65 & 1.03 & -16.53 & 1.68 \\
\hline & \multirow[t]{2}{*}{ High calorie } & Kitchen & Without & 17.89 & 1.04 & -21.33 & 1.50 \\
\hline & & Restaurant & With & 18.06 & 1.08 & -21.10 & 1.41 \\
\hline \multirow[t]{4}{*}{ Controls } & \multirow[t]{2}{*}{ Low calorie } & Kitchen & Without & 4.39 & 0.84 & -1.62 & 1.36 \\
\hline & & Restaurant & With & 4.42 & 0.90 & -2.90 & 1.48 \\
\hline & \multirow[t]{2}{*}{ High calorie } & Kitchen & Without & 4.89 & 0.91 & -3.17 & 1.33 \\
\hline & & Restaurant & With & 4.87 & 0.95 & -3.29 & 1.24 \\
\hline
\end{tabular}

ED, eating disorders; BI, body image.

Finally, $2 \times 2 \times 3$ repeated measures analyses of variance were conducted to test whether there were differences associated with the specific diagnosis (AN, BN, and EDNOS).

\section{Results}

In order to check the assumptions of the repeated measures ANOVA in each of the analyses, the normality of the distributions was assessed by means of Kolmogorov-Smirnov tests. No significant departure from normality was found.

Sphericity was not assessed because the compound symmetry assumption can only be violated when the repeated measures factors have more than two levels. With only two levels, there is only one variance of differences and there is no problem of heterogeneity.

\section{Variations in body-image distortion and dissatisfaction depending on the virtual exposure to food and people in patients and controls}

Repeated measures ANOVAs were conducted in order to test whether participants' body-image distortion and bodyimage dissatisfaction changed depending on the kind of food (low calorie or high calorie), the presence or absence of people in the environment, and the group (ED patients or controls without ED).

Body-image distortion results were only significant for the group variable, $F(1,191)=76.745, p<0.001, \eta^{2}=0.287$, the food variable, $F(1,191)=63.738, p<0.001, \eta^{2}=0.250$, and the interaction between the food and group variables, $F(1$, $191)=38.916, p<0.001, \eta^{2}=0.169$. The effect of the kind of food on body-image distortion differed between the ED and control groups. ED patients showed greater overestimation of their body size when they had to eat high-calorie food (the high-calorie kitchen and the high-calorie restaurant situations) than when they had to eat low-calorie food (the lowcalorie kitchen and the low-calorie restaurant). In contrast, controls showed similar degrees of body-image distortion in all situations (Table 2). The effect of the people variable was not significant.

Similar results were obtained when analyzing body-image dissatisfaction. Once again, only the effect of the group variable, $F(1,192)=77.607, p<0.001, \eta^{2}=0.288$, the food variable, $F(1,192)=26.586, \quad p<0.001, \eta^{2}=0.122$, and the interaction between the food and group variables were

Table 3. Mean Scores for Body-Image Distortion and Body-Image Dissatisfaction of AN, BN, and EDNOS Patients in the Low- and High-Calorie Kitchen, and in the Low- and High-Calorie Restaurant Situations

\begin{tabular}{|c|c|c|c|c|c|c|c|}
\hline & \multirow[b]{2}{*}{ Food } & \multirow[b]{2}{*}{ Situation } & \multirow[b]{2}{*}{ People } & \multicolumn{2}{|c|}{ BI distortion } & \multicolumn{2}{|c|}{ BI dissatisfaction } \\
\hline & & & & $\mathrm{M}$ & SD & $\mathrm{M}$ & SD \\
\hline \multirow[t]{4}{*}{ AN } & \multirow[t]{2}{*}{ Low calorie } & Kitchen & Without & 14.76 & 1.74 & -18.38 & 2.41 \\
\hline & & Restaurant & With & 15.62 & 1.91 & -19.33 & 3.27 \\
\hline & \multirow{2}{*}{ High calorie } & Kitchen & Without & 18.84 & 1.93 & -22.90 & 2.91 \\
\hline & & Restaurant & With & 19.51 & 1.99 & -22.94 & 2.67 \\
\hline \multirow[t]{4}{*}{$\mathrm{BN}$} & \multirow[t]{2}{*}{ Low calorie } & Kitchen & Without & 11.53 & 2.58 & -11.54 & 3.60 \\
\hline & & Restaurant & With & 14.62 & 2.82 & -14.06 & 4.89 \\
\hline & \multirow[t]{2}{*}{ High calorie } & Kitchen & Without & 16.38 & 2.85 & -15.76 & 4.34 \\
\hline & & Restaurant & With & 14.22 & 2.94 & -13.46 & 3.99 \\
\hline \multirow[t]{4}{*}{ EDNOS } & \multirow[t]{2}{*}{ Low calorie } & Kitchen & Without & 12.53 & 3.23 & -19.09 & 4.51 \\
\hline & & Restaurant & With & 11.38 & 3.53 & -10.63 & 6.13 \\
\hline & \multirow[t]{2}{*}{ High calorie } & Kitchen & Without & 16.99 & 3.57 & -24.58 & 5.44 \\
\hline & & Restaurant & With & 19.13 & 3.69 & -26.65 & 4.99 \\
\hline
\end{tabular}


significant, $\left.F(1,192)=11.252, p=0.001, \eta^{2}=0.055\right)$. ED patients showed more dissatisfaction with their body in the two high-calorie food environments than in the two lowcalorie food environments, whereas controls showed similar levels of body dissatisfaction in all the situations. Again, the effect of the people variable was not significant.

\section{Variations in body-image distortion and dissatisfaction depending on food, people, and eating-disorder type}

Repeated measures ANOVAs $(2 \times 2 \times 3)$ were conducted to test whether there were differences depending on the specific ED diagnosis (AN, BN, and EDNOS).

When analyzing levels of body-image distortion, both the effect of the food variable, $F(1,81)=38.874, p<0.001$, $\eta^{2}=0.324$, and the interaction between the food, people, and diagnosis variables were significant, $F(1,81)=3.273$, $\left.p=0.043, \eta^{2}=0.122\right)$. In general, in ED patients, the highcalorie food situations provoked greater body-size overestimation than the low-calorie food situations. However, the interaction between the food, people, and diagnosis variables suggests that the presence or absence of other people could modify the effect of the kind of food, depending on the specific diagnosis of patients. In order to test this hypothesis, $2 \times 2$ (food $\times$ people) repeated measures ANOVAs were conducted for each diagnostic group. Taking the three diagnostic groups (AN, BN, and EDNOS) separately, only the effect of food was significant in $\mathrm{AN}, F(1,47)=24.146, p<0.001 ; \eta^{2}=0.339$, and EDNOS patients, $F(1,13)=12.351, p=0.004, \eta^{2}=0.481$; in BN patients, however, both the effect of food, $F(1,21)=8.688$, $p=0.008, \eta^{2}=0.293$, and the interaction between the food and people variables were significant, $F(1,21)=4.809, p=0.040$, $\eta^{2}=0.186$

As Table 3 shows, AN and EDNOS patients presented higher levels of body-size overestimation after eating highcalorie food than after eating low-calorie food, independently of the presence or absence of people. However, BN patients showed higher levels of body-size overestimation when eating high-calorie food than when eating low-calorie food in the absence of other people, that is, in the kitchen. On the other hand, in the presence of other people (in the restaurant), body-size overestimation was similar when eating both lowand high-calorie food.

The analysis of body-image dissatisfaction data showed that both the effect of food, $F(1,82)=26.226, p<0.001$, $\eta^{2}=0.242$, and the interaction between the food and diagnosis variables, $F(1,82)=4.665, p=0.012, \eta^{2}=0.324$, were significant. The interaction between the food, people, and diagnosis variables was marginally significant, $F(1,82)=$ 2.958, $p<0.058, \eta^{2}=0.067$. As the interaction between food and diagnosis indicates, the effect of food type differs depending on the diagnosis. EDNOS and AN patients presented much greater body dissatisfaction after eating high-calorie food than after eating low-calorie food, but the difference in BN patients, while present, was only slight. In fact, the effect of food type was only significant in the AN, $F(1,48)=25.743, p<0.001, \eta^{2}=0.349$, and EDNOS subgroups, $F(1,13)=5.140, p=0.041, \eta^{2}=0.283$.

In order to analyze the interaction between the food, people, and diagnosis variables, $2 \times 2$ (food $\times$ people) repeated measures ANOVAs were then conducted for each diagnostic subgroup. The results showed that in AN, $F(1,47)=25.743$, $p<0.001, \eta^{2}=0.349$, and EDNOS patients, $F(1,13)=5.140$, $p=0.041, \eta^{2}=0.283$, only the effect of the food variable was significant. Unexpectedly, in the BN group, no effect was significant. As Table 3 shows, BN patients reported lower levels of body-image dissatisfaction than the other diagnostic subgroups.

\section{Discussion}

Using VR, this study aimed to test whether body-image disturbances, specifically body-image distortion and bodyimage dissatisfaction, change depending on the situation to which participants are exposed, and also to determine whether responses to these situations differ in ED patients and non-ED controls.

The contextual cues analyzed were the kind of food (low calorie or high calorie) and the presence or absence of other people in the VEs. In this study, body-image distortion is understood as the discrepancy between perceived and objective body size, and body-image dissatisfaction is understood as the discrepancy between ideal and perceived body size.

As expected, patients with ED showed higher levels of body-image distortion and body-image dissatisfaction than controls after visiting all the VEs. Furthermore, ED patients presented greater body-image distortion (body-size overestimation) and body-image dissatisfaction after eating highcalorie food than after eating low-calorie food. In contrast, non-ED controls did not show changes in body image depending on the situation. Other studies have obtained similar results. Crisp and Kalucy ${ }^{12}$ were the first to assess experimentally the impact of food on the body image of ED patients. They found that women with AN showed greater body-image distortion after eating a meal perceived to be high in carbohydrates. Similarly, other studies have found that BN participants estimate their actual body size to be larger after being exposed to high-calorie food, whereas controls do not. ${ }^{34,35,37,38,95}$

In view of the evidence of a close relationship between social anxiety and eating disorders, ${ }^{83,96-101}$ we expected that the presence or absence of people would also exert a significant effect on body-image disturbances in our ED subjects. Surprisingly, however, neither the people variable nor the interaction between the food and people variables had a significant effect on body-image distortion and body-image dissatisfaction.

These results could be explained by the fact that the presence of people in a restaurant does not imply a great level of body scrutiny. As Haimovitz et al. ${ }^{31}$ stressed, body-image experience reflects how participants feel about their bodies. They exposed 144 female undergraduates to four situations using guided imagery. They found that situations in which participants were especially self-critical about their bodiessuch as walking past a group of attractive people at the beach in a bathing suit or trying on bathing suits in the dressing room of a department store-elicit higher levels of dissatisfaction than "everyday situations," such as having a conversation with a close female friend over lunch or getting dressed in private. It is likely that having lunch with friends in a restaurant, as in the case of our VE, does not make ED patients feel self-critical enough to impact on their body image, whereas eating high-calorie food does. 
Several authors have stressed that ED patients check their body shape significantly more often than people without this pathology. ${ }^{102}$ Among body-checking examples, such as looking repeatedly in the mirror, frequent weighing, using special kinds of clothes that allow patients to control their thinness or fatness, and pinching flesh, comparing with their shape and appearance with those of other people have frequently been recorded. ${ }^{14,103,104}$ Body checking has been related to an increase in body distortion and body dissatisfaction; ${ }^{64,102,105,106}$ moreover, an association has been hypothesized between social physique anxiety, the fear of negative appearance evaluation in social contexts, and body checking. ${ }^{107}$ Consequently, body checking could have been expected to increase body-size distortion and body-image dissatisfaction in the virtual restaurant situations, in which the participant is accompanied by others. Nevertheless, the fact that the participant's body did not appear in the scenario (since the exposure to the VE was made from the first-person perspective), the fact they could not touch themselves during the exposure (since they had to use the mouse with the right hand and the keyboard with the left), and the fact that they could not see their bodies (since the experimental situation was conducted in a dark room) prevented them from checking their bodies.

Having clarified that body-image disturbances change depending on the situation, we wanted to explore whether there were variations between the different diagnostic groups. When analyzing the effect of the food and people variables on body-image disturbances in the whole sample, only food was found to have a significant effect. However, when body-image distortion was analyzed by considering the three diagnostic groups separately, a significant interaction between the food, people, and diagnosis variables appeared. Repeated measures ANOVAs for each diagnostic subgroup showed that while only the effect of the food variable was significant in AN and EDNOS patients, in BN patients, the interaction between the food and people variables was also significant. When they were alone, as happened in the kitchen, BN patients showed much greater body-size overestimation after eating high-calorie food than after eating low-calorie food. In contrast, in the restaurant, where the participant was accompanied by other people, body-image distortion levels were similar, regardless of the kind of food.

There are several possible explanations for the differential effect of the people variable in the AN and BN groups. First, $\mathrm{BN}$ patients are especially sensitive to social interactions. ${ }^{97,98,108,109}$ Steiger et al. ${ }^{109}$ state that binge-eating episodes are often triggered by negative social experiences, and that these behaviors maintain the negative experiences. Similarly, Hinrichsen et al. ${ }^{110}$ found that higher levels of social anxiety were associated with higher levels of bulimic psychopathology in $\mathrm{BN}$, and with higher levels of dissociation in restrictive AN. This could explain the differential reaction of $\mathrm{BN}$ and $\mathrm{AN}$ patients to the presence of people in the VEs. BN participants may tend to reduce the impact of social anxiety by engaging in binge eating and purging behaviors, whereas AN participants tend to reduce it through a process of cognitive avoidance. Through this process, restrictive AN patients avoid threatening social information and, consequently, reduce their level of affect-driven responding. ${ }^{110} \mathrm{It}$ could be hypothesized that when AN patients visit both lowand high-calorie virtual restaurants, where participants have lunch accompanied with friends, they avoid processing the information from the presence of people and block the emotional and cognitive responses associated with this situation. Moreover, AN patients tend to be more internally focused, and $\mathrm{BN}$ patients are more externally focused; the attention of patients with anorexia nervosa is centered on everything related with food and how to lose weight, while the attention of bulimics is more centered on the judgments that others may make. It is possible that when $\mathrm{BN}$ patients are alone, as happened in the kitchen VE, they focus on the food and on their concerns about putting on weight. In this situation, eating high-calorie food would enhance the overestimation of body-image size. On the other hand, when $\mathrm{BN}$ patients are accompanied in a restaurant, they may focus more on people and the comments they make (which are exactly the same in both restaurants in the VE), and thus the effect of food diminishes or even disappears.

Differences between BN patients and the other diagnostic groups appear again when studying body-image dissatisfaction. In the AN and EDNOS groups, only the effect of the food variable is significant; in the BN group, none of the individual variables have any significant effect on body dissatisfaction, that is, they show similar levels of body-image dissatisfaction across the different situations. Other studies have emphasized the stability of body dissatisfaction in BN patients. ${ }^{34,95}$ These results suggest that body-image dissatisfaction acts more like a trait than a state in BN patients, but not in AN participants.

Other authors ${ }^{45}$ have suggested that body-image dissatisfaction could be due to cognitions about the expected effects of food intake instead of the direct effects of eating, and that these cognitions may differ depending on the characteristics of the participant. Lattimore et al., ${ }^{45}$ for example, found that when visual high-calorie-food cues were available, eating increased body-image dissatisfaction in overweight participants compared with lean ones; in the absence of such visual cues, however, eating high-calorie food reduced body-image dissatisfaction in overweight participants, but tended to increase it in lean participants. These results show that the presence of food cues plays a role in triggering food-related changes in body dissatisfaction. More research comparing restrictive anorexia patients and bulimic patients is needed to explore these diagnostic differences further.

\section{Conclusions}

Body-image distortion and body-image dissatisfaction can be influenced by situational factors. VR exposure is a useful technology for their study. Events or stimuli that trigger body-weight and body-image concerns, for example, eating high-calorie food, lead to increased body-image disturbances in patients with ED. In contrast, these stimuli seem to have no effect on the body image of participants without ED, probably because they are not emotionally significant for them.

The results support those of earlier studies suggesting that body-image distortion and body-image dissatisfaction refer to both stable and dynamic aspects. ${ }^{27,29}$ Corroborating this previous research, our study shows the presence of a predisposition to a more distorted and dissatisfied body image in patients than in controls, and also highlights the fact that, in the patient group, these body-image 
disturbances fluctuate depending on emotional and situational variables.

The stability/instability of body-image disturbances also seems to be influenced by the specific diagnosis of participants, as body-image dissatisfaction in BN patients is a stable variable in this study. However, the sample size of the three diagnostic groups is small, and these results should therefore be treated with caution.

The present study has several implications for clinical practice. First, given that body-image disturbances act more as a state than a trait, physicians should consider the physical and psychological context of the participant when assessing body-image distortion and body-image dissatisfaction. Second, in a therapeutic context, the combined use of bodyimage assessment tools and VR exposure to specific key events or stimuli could provide clear, therapist-independent information to patients about their subjective views of their bodies, since their perception and judgments change depending on the situation to which they are exposed. Third, the treatment of body-image disturbances in ED should include the identification of and intervention with those aspects that enhance the patient's body-image disturbance. In this regard, further research is required to identify the specific aspects that trigger body-image disturbances in ED patients, as well as the interpretations they make about situations. More studies are also needed to compare the functioning of body-image disturbances in restrictive anorexic and bulimic patients.

Finally, the study has several limitations that should be taken into account in future research. Several issues related to the sample should be considered. First, the ED group consisted of both inpatients and day hospital outpatients, so it is a heterogeneous group that includes different levels of severity of pathology and treatment time. For its part, the control group was composed of psychology students; it may not constitute a representative community group, and in fact is unlikely to share the same socio-demographic characteristics as the experimental group. These features should be borne in mind when interpreting the results. Second, although the sample size is adequate for our study and in fact larger than in most similar studies, the division into diagnostic subgroups will produce more significant results if larger populations are used. Moreover, some possibly moderating variables, such as the severity of symptoms, the BMI, the dietary behaviors, and hormonal changes associated with menstrual cycle, were not taken into account. These variables should be considered in future research.

\section{Acknowledgments}

We would like to express our thanks to Luís SánchezPlanell from the Hospital Germans Trias i Pujol, Elena Moreno from the Hospital Clínic, Sonia Ferri from the ABB Centre, Maria Ortega from the LABOR Centre, and to all participants for their cooperation. This study was supported by the Spanish Ministry of Education and Science (Consolider Project SEJ2006-14301/PSIC: "New information and communication technologies: Integration and consolidation of its use in social sciences to improve health, quality of life and well-being"; and the Research Project SEJ2005-09170-C04-01) and by a scholarship from La Caixa ("Obra Social") granted to the second author.

\section{Disclosure Statement}

No competing financial interests exist.

\section{References}

1. Edman JL, Yeates A, Aruguete MS, et al. Negative emotion and disordered eating among obese college students. Eating Behavior 2005; 6:308-17.

2. Stice E, Shaw HE. Role of body dissatisfaction in the onset and maintenance of eating pathology a synthesis of research findings. Journal of Psychosomatic Research 2002; 53:985-93.

3. Bruch H. Perceptual and conceptual disturbances in anorexia nervosa. Psychosomatic Medicine 1962; 24:187-94.

4. Rosen JC. (1990) Body-image disturbances in eating disorders. In Cash TF, Pruzinsky T, eds. Body Images: Development, deviances and change. New York: Guilford Press, pp. 190-214.

5. Gleaves DH, Eberenz K. The psychopathology of anorexia nervosa: A factor analytic investigation. Journal of Psychopathology \& Behavioural Assessment 1993, 15:141-52.

6. Striegel-Moore RH, Franko DL,Thompson D, et al. Changes in weight and body image over time in women with eating disorders. International Journal of Eating Disorders 2004; 36:315-27.

7. Vanardo PJ, Williamson DA, Netemeyer SB. Confirmatory factor analysis of eating disorder symptoms in college women. Journal of Psychopathology \& Behavioural Assessment 1995; 17:69-79.

8. American Psychiatric Association. (1994) Diagnostic and statistical manual of mental disorders. Washington, DC: American Psychiatric Association.

9. Cash TF. (1996) The treatment of body image disturbances. In Thompson JK, ed. Body image, eating disorders, and obesity: An integrative guide for assessment and treatment. Washington, DC: American Psychological Association, pp. 83107.

10. Striegel-Moore RH, Cachelin FM. Etiology of eating disorders in women. The Counseling Psychologist 2001; 29:635-61.

11. Cash TF, Deagle EA. The nature and extend of body image disturbances in anorexia nervosa and bulimia nervosa: A meta-analysis. International Journal of Eating Disorders 1997; 22:107-25.

12. Crisp AH, Kalucy RS. Aspects of the perceptual disorder in anorexia nervosa. British Journal of Medical Psychology 1974; 47:349-61.

13. Freeman RJ, Beach B, Davis R, et al. The prediction of relapse in bulimia nervosa. Journal of Psychiatric Research 1985; 19:349-53.

14. Rosen JC. (1997) Cognitive-behavioral body image therapy. In Garner DM, Garfinkel PE, eds. Handbook of treatment for eating disorders. New York: Guilford Press, pp. 188-201.

15. Slade PD, Russell GFM. Awareness of body dimensions in anorexia nervosa: Cross sectional and longitudinal studies. Psychological Medicine 1973; 3:188-99.

16. Skrzypek S, Wehmeier PM, Remschmidt H. Body image assessment using body size estimation in recent studies on anorexia nervosa. A brief review. European Child \& Adolescent Psychiatry 2001; 10:215-21.

17. Bowden PK, Touyz, SW, Rodriguez PJ, et al. Distorting patient or distorting instrument? The British Journal of Psychiatry 1989; 155:196-201.

18. Garner DM, Garfinkel PE. Body image in anorexia nervosa: Measurement, theory and clinical implications. International Journal of Psychiatry in Medicine 1981; 11:263-84. 
19. Hsu LKG, Sobkiewick TA. Body image disturbance: Time to abandon the concept for eating disorders? International Journal of Eating Disorders 1991; 10:15-30.

20. Slade PD, Brodie D. Body image distortion and eating disorder: A reconceptualitation based on recent literature. European Eating Disorders Review 1994; 1:32-46.

21. Sepúlveda AR, Botella J, León, JK. La alteración de la imagen corporal en los trastornos de la alimentación: Un meta-análisis. Psicothema 2001; 13:7-16.

22. Smeets MAM. The rise and fall of body size estimation research in anorexia nervosa: A review and reconceptualization. European Eating Disorders Review 1997; 5:75-95.

23. Thompson JK. (1996) Body image, eating disorders and obesity. Washington, DC: American Psychological Association.

24. Cash TF, Fleming EC, Alindogan J, et al. Beyond body image as a trait: The development and validation of the Body Image States Scale. Eating Disorders 2002; 10:103-13.

25. Melnyck SE, Cash TF, Janda LH. Body image ups and downs: Prediction of intra-individual level and variability of women's daily body image experiences. Body Image 2004; 1:225-35.

26. Tiggermann M. Person $\times$ situation interactions in body dissatisfaction. International Journal of Eating Disorders 2001; 29:65-70.

27. Myers PN, Biocca FA. The elastic body image: The effect of television advertisement and programming on body image distortions in young women. Journal of Communication 1992; 42:108-33.

28. Etu SF, Gray JJ. A preliminary investigation of the relationship between induced rumiation and state body image dissatisfaction and anxiety. Body Image 2009. DOI: 10.1016/ j.bodyim.2009.09.004.

29. Lattimore P, Hutchinson R. Perceived calorie intake and state body-image satisfaction in women attempting weight loss: A preliminary investigation. Body Image 2009. DOI: 10.1016/j.bodyim.2009.08.002.

30. Rudiger JA, Cash TA, Roehrig M, et al. Day-to-day bodystates: Prospective predictors of intra-individual level of variability. Body Image 2007; 4:1-9.

31. Haimovitz D, Lansky LM, O'Reilly P. Fluctuations in body satisfaction across situations. International Journal of Eating Disorders 1993; 13:77-84.

32. Roth D, Armstrong J. Feelings of fatness questionnaire: A measure of the cross-situational variability of body experience. International Journal of Eating Disorders 1993; 14:349-58.

33. Wardle J, Foley E. Body image: Stability and sensitivity of body dissatisfaction and body size estimation. International Journal of Eating Disorders 1989; 8:55-62.

34. McKenzie SJ, Williamson DA, Cubic BA. Stable and reactive body image disturbance in bulimia nervosa. Behavior Therapy 1993; 24:195-207.

35. Vocks S, Legenbauer T, Heil A. Food intake affects state body image: Impact of restrained eating patterns and concerns about eating, weight and shape. Appetite 2007; 49:467-75.

36. Carter F, Bulik CM. Exposure treatments for bulimia nervosa: Procedure, efficacy, and mechanisms. Advances in Behavior Research \& Therapy 1994; 16:77-129.

37. Coelho JS, Carter JC, McFarlane T, et al. Just looking food makes me gain weight: Experimental induction of thoughtshape fusion in eating disordered and non-eating disordered women. Behavior Research Methods 2008; 46:219-28.

38. Geschwind N, Roefs A, Jansen A, et al. Dietary restraint modulates the effects of food cue exposure on women's body and weight satisfaction. Appetite 2008; 51:735-8.
39. Heilbrun AB, Flodin A. Food cues and perceptual distortion of the female body: Implications for food avoidance in the early dynamics of anorexia nervosa. Journal of Clinical Psychology 1989; 45:843-50.

40. Laberg JC, Wilson GT, Eldredge K, et al. Effects of mood on heart rate reactivity in bulimia nervosa. International Journal of Eating Disorders 1991; 10:169-78.

41. Cash T, Cash DW, Butters JW. "Mirror, mirror, on the wall ... ?" Contrast effects and self-evaluations of physical attractiveness. Personality \& Social Psychology Bulletin 1983; 9:351-8.

42. Fett AK, Lattimore $P$, Roefs A, et al. Food cue exposure and body image satisfaction: The moderating role of BMI and dietary restraint. Body Image 2009; 6:14-18.

43. Gardner RM, Espinoza T, Urrutia R, et al. The effect of hunger on the obese: Feeling full, feeling fat. The Psychiatric Forum 1990; 15:57-62.

44. Lattimore P. Body dissatisfaction in females varies according to deprivation state and is modified by weight rather than restraint status. Appetite 2005; 45:356-9.

45. Lattimore P, Roefs A, Jansen A, et al. 2008 High-calorie food affects body and weight dissatisfaction in females as a function of food cue availability and body mass index. Unpublished manuscript.

46. Pietrowsky R, Straub K, Hachl P. Body dissatisfaction in female restrainer eaters depends on food deprivation. Appetite 2003; 40:285-90.

47. Groesz L, Levine M, Turnen S. The effect of experimental presentation of thin media images in body dissatisfaction: A meta-analytic review. International Journal of Eating Disorders 2002; 31:1-16.

48. Harrison K, Cantor J. The relationship between media consumption and eating disorders. The Journal of Communication 1997; 47:40-67.

49. Hawkins N, Richards PS, Granley HM, et al. The impact of exposure to the thin-ideal media image on women. Eating Disorders 2004; 12:35-50.

50. Heinberg LJ, Thompson JK. Body image and televised images of thinness and attractiveness: A controlled laboratory investigation. Journal of Social \& Clinical Psychology 1995; 14:325-38.

51. Krones PG, Stice E, Batres C, et al. In vivo social comparison to a thin-ideal peer promotes body dissatisfaction: $\mathrm{A}$ randomized experiment. International Journal of Eating Disorders 2005; 38:134-42.

52. Tiggemann M, McGill B. The role of social comparison in the effect of magazine advertisements on women's mood and body dissatisfaction. Journal of Social \& Clinical Psychology 2004; 23:23-4.

53. Stice E, Shaw HE. Adverse effects of the media portrayed thin-ideal on women and linkages to bulimic symptomatology. Journal of Social \& Clinical Psychology 1994; 13:288-308.

54. Slater M, Pertaub DP, Barker C, et al. An experimental study on fear of public speaking using a virtual environment. CyberPsychology \& Behavior 2006; 9:627-33.

55. Ferrer-García M, Gutiérrez-Maldonado J, Caqueo-Urízar A, et al. The validity of virtual environments for eliciting emotional responses in patients with eating disorders and in controls. Behavior Modification 2009; 3:830-54.

56. Pallister E, Waller G. Anxiety and eating disorders: Understanding the overlap. Clinical Psychology Review 2008; 28: 366-86. 
57. Saldaña C, Tomás I, Bach L. Técnicas de intervención en los trastornos del comportamiento alimentario. Ansiedad y Estrés 1997; 3:319-37.

58. Kulbartz-Klatt YK, Florin I, Pook M. Bulimia nervosa: Mood changes do have an impact on body width estimation. British Journal of Clinical Psychology 1999; 38:279-87.

59. Rotenberg KJ, Taylor D, Davies R. The induced disparagement and enhancement of body image effect: Are they due to cognitive priming or subjective mood? International Journal of Eating Disorders 2004; 35:317-32.

60. Taylor MJ, Cooper PJ. An experimental study of the effects of mood on body size perception. Behaviour Research \& Therapy 1992; 30:53-8.

61. Hoffman DS. Media exposure, body dissatisfaction and depressive symptoms during adolescence: Daily fluctuations and moderating influences. Dissertation Abstracts International: Section B: The Sciences \& Engineering 2007; 67:5406.

62. Rodin, J, Silberstein L, Striegel-Moore R. Women and weight: A normative discontent. Nebraska Symposium on Motivation 1984; 32:267-307.

63. Williamson DA, Muller SL, Reas DL, et al. Cognitive bias in eating disorders: Implications for theory and treatment. Behavior Modification 1999; 23:556-77.

64. Williamson DA, White MA, York-Crowe E, et al. Cognitive-behavioral theories of eating disorders. Behavior Modification 2004; 28:711-38.

65. Cash TF, Brown TA. Body image in anorexia nervosa and bulimia nervosa: A review of the literature. Behavior Modification 1987; 11:487-521.

66. Thompson JK. (1990) Body image disturbance: Assessment and treatment. Elmsford, NY: Pergamon Press.

67. Schienle A, Schäfer A, Hermann A, et al. Binge-eating disorders: Reward sensitivity and brain activation to images of food. Biological Psychiatry 2009; 65:654-61.

68. Riva G. Modifications of body-image induced by virtual reality. Perceptual Motor Skills 1998a; 86:163-70.

69. Riva G. Virtual environment for body image modification: Virtual reality system for treatment of body image disturbances. Computers in Human Behavior 1998b; 14:477-90.

70. Riva G. Virtual reality in psychological assessment: The body image virtual reality scale. CyberPsychology \& Behavior 1998c; 1:37-44.

71. Riva G, Bacchetta M, Baruffi M, et al. Virtual reality environment for body image modification: A multidimensional therapy for the treatment of body image in obesity and related pathologies. CyberPsychology \& Behavior 2000; 3:421-31.

72. Riva G, Bacchetta M, Baruffi M, et al. Virtual reality-based multidimensional therapy for the treatment of body image disturbances in obesity: A controlled study. CyberPsychology \& Behavior 2001; 4:511-26.

73. Riva G, Bacchetta M, Baruffi M, et al. (1998) Experiential cognitive therapy: A VR based approach for the assessment and treatment of eating disorders. In Riva G, Wiederhold BK et al. eds. Virtual environments in clinical psychology and neuroscience: Method and techniques in advanced patienttherapist interaction. Amsterdam, Netherlands: IOS Press, pp. 120-35.

74. Riva G, Bacchetta M, Baruffi M, et al. Virtual reality based experiential cognitive treatment of obesity and binge-eating disorders. Clinical Psychology \& Psychotherapy 2000; 7:209-19.
75. Riva G, Bacchetta M, Cesa G, et al. Six-month follow-up of in-patient experiential-cognitive therapy for binge eating disorders. CyberPsychology \& Behavior 2003; 6:251-8.

76. Riva G, Melis L. (1997) Virtual reality for the treatment of body image disturbances. In Riva G, ed. Virtual reality in neuro-psycho-physiology. Amsterdam, Netherlands: IOS Press, pp. 95-111.

77. Riva G, Melis L, Bolsón M. Treating body image disturbances. Communications of the ACM 1997; 40:69-71.

78. Perpiñá C, Botella C, Baños RM. (2002) Body image in eating disorders. Valencia, Spain: Promolibro.

79. Perpiñá $C$, Botella $C$, Baños RM, et al. Body image and virtual reality in eating disorders: Exposure by virtual reality is more effective than the classical body image treatment? CyberPsychology \& Behavior 1999; 2:149-59.

80. Perpiñá $\mathrm{C}$, Marco JH, Botella $\mathrm{C}$, et al. Tratamiento de la imagen corporal en los trastornos alimentarios mediante tratamiento cognitivo-comportamental apoyado con realidad virtual: Resultados al año de seguimiento. Psicología Conductual 2003; 12:519-37.

81. Murray CD, Gordon MS. Changes in bodily awareness induced by immersive virtual reality. CyberPsychology \& Behavior 2001; 4:365-71.

82. Bulik CM, Beidel DC, Duchmann E, et al. An analysis of social anxiety in anorexic, bulimic, social phobic, and control women. Journal of Psychopathology \& Behavioral Assessment 1991; 13:199-211.

83. Tomas I, Bach L, Saldaña C. Técnicas de intervención en los trastornos del comportamiento alimentario. Ansiedad y Estrés 1997; 3:319-37.

84. Gutiérrez-Maldonado J, Ferrer-García M, Caqueo-Urízar A, et al. Assessment of emotional reactivity produced by exposure to virtual environments in patients with eating disorders. CyberPsychology \& Behavior 2006; 9:507-13.

85. Garner DM, Olmsted MP, Bohr Y, et al. The eating attitudes test: Psychometric features and clinical correlates. Psychological Medicine 1982; 12:871-8.

86. Garner DM, Garfinkel PE. Body image in anorexia nervosa: Measurement, theory and clinical implications. International Journal of Psychiatry in Medicine 1981; 11:263-84.

87. Garner DM, Olmsted MP, Bohr Y, et al. Development and validation of a multidimensional eating disorders inventory for anorexia nervosa and bulimia. International Journal of Eating Disorders 1983; 2:15-34.

88. Gonzalo D. (1995) Protocolo de trastornos del comportamiento alimentario. Instituto Nacional de la Salud. Madrid, Spain: Secretaría General.

89. Bulbena A, Berrios GE, Fernández de Larrinoa P. (2000) Medición Clínica en Psiquiatría y Psicología. Barcelona, Spain: Masson.

90. Jorquera M, Botella-Garneria C, Guillen V, et al. (2006) El "Test de Actitudes hacia la comida-26": Validación en una muestra española. VII Congreso Virtual de Psiquiatría: Interpsiquis.

91. Letosa-Porta A, Ferrer-García M, Gutiérrez-Maldonado J. A program for assessing body-image disturbance using adjustable partial image distortion. Behavior Research Methods, Instruments \& Computers 2005; 37:638-43.

92. Ferrer-García M, Gutiérrez-Maldonado J. Body image assessment software: Psychometric data. Behavior Research Methods 2008; 40:394-407.

93. Spielberger CD, Gorsuch RL, Lushene RE. (1970) Handbook of STAI. Palo Alto, CA: Consulting Psychologist Press 
[Spanish adaptation: Seisdedos, N. (1988) Barcelona, Spain: Ediciones TEA].

94. Pérez B, Gutiérrez J, Ferrer M. (2004) Cuestionario de Depresión Barcelona: Evaluación del curso de la depresión. VII European Conference on Psychological Assessment.

95. Carter FA, Bulick CM, Lawson RH, et al. Effect of mood and food cues on body image in women with bulimia and controls. International Journal of Eating Disorders 1996; 20:65-76.

96. Brewerton TD, Lydiard RB, Ballenger JC, et al. Eating disorders and social phobia. Archives of General Psychiatry 1993; 50:70-9.

97. Godart NT, Flament MF, Curt F, et al. Anxiety disorders in subjects seeking treatment for eating disorders: A DSM-IV controlled study. Psychiatry Research 2003; 117: 245-58.

98. Grabhorn R, Stenner H, Stangier U, et al. Social anxiety in anorexia and bulimia nervosa: The mediating role of shame. Clinical Psychology \& Psychotherapy 2006; 13:12-19.

99. Halmi KA, Eckert E, Marchi P, et al. Comorbidity of psychiatric diagnoses in anorexia nervosa. Archives of General Psychiatry 1991; 48:712-18.

100. McLean CP, Miller NA, Hope DA. Mediating social anxiety and disordered eating: The role of expressive suppression. Eating Disorders 2007; 15:41-54.

101. Toro J, Gila A, Castro J, et al. Body image, risk factors for eating disorders and sociocultural influences in Spanish adolescents. Eating \& Weight Disorders 2005; 10:91-7.

102. Shafran R, Fairburn CG, Robinson P, et al. Body checking and its avoidance in eating disorders. International Journal of Eating Disorders 2004; 35:93-101.

103. Fairburn CG, Cooper Z, Shafran R. Cognitive behaviour therapy for eating disorders: A "transdiagnostic" theory and treatment. Behaviour Research \& Therapy 2003; 41:509-28.
104. Reas DL, Whisenhunt BL, Netemeyer R, et al. Development of the body checking questionnaire: A self-report measure. International Journal of Eating Disorders 2002; 31:324-33.

105. Fairburn CG. (1997) Eating disorders. In Clark DM, Fairburn CG, eds. Science and practice of cognitive behaviour therapy. Oxford, England: Oxford University Press, pp. 209-43.

106. Fairburn CG, Shafran R, Cooper Z. A cognitive-behavioural theory of anorexia nervosa. Behaviour Research \& Therapy 1999; 37:1-13.

107. Haase AM, Mountford V, Waller G. Understanding the link between body checking cognitions and behaviors: The role of social physique anxiety. International Journal of Eating Disorders 2007; 40:241-6.

108. Grabhorn R, Stenner H, Kaufhold J, et al. Scham und soziale Angst bei Anorexia und Bulimia. Zeitschrift für Psychosomatische Medizin und Psychotherapie 2005; 52:179-93.

109. Steiger H, Gauvin L, Jabalpurwala S, et al. Hypersensitivity to social interactions in bulimic eating syndromes: Relationship to binge eating. Journal of Consulting \& Clinical Psychology 1999; 67:765-75.

110. Hinrichsen $H$, Wright F, Waller G, et al. Social anxiety and coping strategies in the eating disorder. Eating Behavior 2003; 4:117-26.

Address correspondence to: Marta Ferrer-García Dept. of Personality, Assessment and Psychological Treatments University of Barcelona Valle de Hebron, 171 08035 Barcelona Spain

E-mail: martaferrerg@ub.edu 
